\title{
Fouling Behaviour During Cross Flow Ultrafiltration of Cassava Starch Hydrolysate Using Polyacrylonitrile Membrane
}

\author{
Received in revised form 1 July 2005, accepted 1 July 2005
}

\section{N. Widiasa ${ }^{1} \&$ I. G. Wenten ${ }^{2 *}$}

${ }^{1}$ Dept. of Chemical Engineering, Diponegoro University, Kampus Tembalang, Semarang, Indonesia, 50239

${ }^{2}$ Dept, of Chemical Engineering, Institut Teknologi Bandung, Jl. Ganesha 10 Bandung, Indonesia, 40132

\begin{abstract}
Ultrafiltration (UF) is considered as a promising alternative to the traditional clarification techniques in the sugar industries. In this work, a hollow fiber UF membrane (polyacrylonitrile, MWCO $100 \mathrm{kDa}$ ) was used for clarification of cassava starch hydrolysate. The influence of various operating parameters, such as transmembrane pressure (TMP), cross flow velocity and $\mathrm{pH}$ hydrolysate on the membrane fouling was assessed. The results showed that TMP higher than 1.0 bar was not effective to improve flux. Increasing cross flow velocity was virtually effective to reduce permeate flux decline. The steady state flux, $\mathrm{J}_{\mathrm{ss}}$ increased significantly when $\mathrm{pH}$ of the feed was adjusted to alkaline condition; however, this resulted in dark brown clarified glucose syrup. Operating at natural $\mathrm{pH}$ of 4.5 , the membrane selectivity was close to $100 \%$. Evaluation of hydraulic resistance indicated that concentration polarization and pore blocking were beyond approximately 50 and $40 \%$ of the total filtration resistance, respectively. Moreover, scanning electron microscopy showed that extensive fouling layer was deposited on the membrane surface. Finally, the developed cleaning procedure could restore membrane performance approximately $45 \%$ of its initial performance.
\end{abstract}

Keyzords : Cassava starch hydrolysate, glucose syrup, ultrafiltration

\subsection{INTRODUCTION}

Conversion of starch to glucose syrup is a commercially important process. Glucose syrup may be used in the production of pure dextrose, high fructose syrup, as sweetener, and as substrate in fermentation processes [1]. In the United States, glucose is manufactured from corn starch; in Europe from corn starch and potato starch; in Japan from corn starch and white sweet potato starch [2] and in tropical countries, such as Thailand, Vietnam, and Indonesia, from cassava starch. As with other starches, cassava starch contains various impurities such as protein $(0.11 \%)$, fat $(0.07 \%)$, fiber $(0.12 \%)$, and ash $(0.25 \%)$ [3]. After the saccharification is complete, the cassava starch hydrolysate is clarified to remove suspended solid, fat, protein, and other impurities. This is generally performed by rotary vacuum precoat filters (RVPF) with diatomaceous earth as filter-aid [4-6]. Microporous ceramic membrane can be used for clarification of starch hydrolysate more efficiently [7].

\footnotetext{
*Correspondence to: I. G. Wenten (tel/fax: 62-22-2511404, e-mail: igw@che.itb.ac.id)
} 
Recently, the technical feasibility of ultrafiltration (UF) using polymer membranes for process improvement in sugars industry has been intensively explored. Due to much lower price of the polymer membranes, they may be competitive to ceramic membrane. Most studies were directed on the cane and beet sugars clarification [8-13]. Since the cassava starch hydrolysate has moderate temperature and $\mathrm{pH}$, we are convinced that UF system using a polymer membrane can be one of the cost-effective solutions.

A major problem of the ultrafiltration application for clarification of cassava starch hydrolysate is membrane fouling. Although the hydrolysate contains less than $1 \%$ of impurities, it may be sufficient to cause a significant loss of filtration rate. Fouling is the irreversible alteration in the membrane caused by specific physical and/or chemical interactions between the membrane and various components present in the process stream [14]. These interactions can be attributed to one or more of the following mechanisms: (a) adsorption, (b) gel layer formation, and (c) plugging of the membrane pores [15]. Its severity depends on the membrane material, the nature of solutes, and other variables such as $\mathrm{pH}$, ionic strength, solution temperature and operating pressure [16]. Fouling effect is characterized by an irreversible decline in flux with time of operation when all operating parameters, such as transmembrane pressure, flow rate, temperature, and feed concentration are kept constant [17]. Membrane fouling often continues throughout the process and eventually requires extensive cleaning or replacement of the membrane. Therefore, the successful development of this application requires a comprehensive understanding of fouling phenomenon to maximize the membrane performance.

The aim of this study is to assess the effect of operating parameters, such as TMP, cross flow velocity, and $\mathrm{pH}$ hydrolysate on fouling behaviour during clarification of cassava starch hydrolysate using polyacrynitrile (PAN) membrane. A series resistance model [18] was used to analyze the mass transfer resistances.

\subsection{EXPERIMENTAL}

\subsection{Feed Solution}

For this study, cassava starch hydrolysate was prepared by enzymatic hydrolysis of a commercial cassava starch using $\alpha$-amylase (Termamyl 120L) and glucoamylase (AMGE), respectively. The two enzymes were supplied by Raya Sugarindo Inti Co. The hydrolysate had total solids of $30-50 \%$, suspended solids of $0.3 \%$, nitrogen content of $350 \mathrm{ppm}, \mathrm{pH}$ of $4.5-5.0$, and dextrose equivalent approximately 96 . Dextrose equivalent (DE) represents either the percentage hydrolysis of the glycosidic linkages or the degree of conversion of the starch molecules to the glucose molecules. The hydrolysate was adjusted to the desired $\mathrm{pH}$ with either $2 \mathrm{~N} \mathrm{NaOH}$ or $2 \mathrm{~N} \mathrm{HCl}$ solutions. The hydrolysate was prefiltered by a 200 mesh to remove large particles prior to be pumped through the UF module. For every experiment, fresh hydrolysate was prepared.

\subsection{Ultrafiltration Equipment}

Clarification of cassava starch hydrolysate was carried out using the experimental set-up depicted in Figure 1, which consists of a stirred stainless steel vessel, a hollow fiber membrane module, a diaphragm pump (Puricom UP-8000, maximum flow rate of $3 \mathrm{lpm}$, maximum pressure of $80 \mathrm{psi}$, motor $48 \mathrm{VDC} / 2 \mathrm{~A} / 50 \mathrm{hz}$ ), a flow rate regulator (adjustable DC power supply), and two pressure regulators (needle valve). The membrane module used hollow fiber polyacrylonitrile (PAN) membranes that were supplied by GDP Filter Co. Characteristics of the hollow fiber module are 
Table 1 Characteristics of the hollow fiber module

\begin{tabular}{lc}
\hline Material & PAN \\
\hline Molecular weight cut-off & $100 \mathrm{kDa}$ \\
Inside diameter & $0.5 \mathrm{~mm}$ \\
Thickness & $0.2 \mathrm{~mm}$ \\
Effective length & $25 \mathrm{~cm}$ \\
Effective area & $82.4 \mathrm{~cm}^{2}$ \\
\hline
\end{tabular}

shown in Table 1. The system was also completed with automatic temperature control (regulated water bath) and pressure indicator (FTB, 0-60 psi).

\subsection{Experimental Procedure}

In this study, a total recycle mode was used, i.e., both permeate and retentate were returned to the feed tank to maintain the feed characteristic relatively constant. To avoid the effect of membrane compaction, deionized water was recirculated at TMP of 4 har for 2 hours prior to the use of the cassava starch hydrolysate. The effect of operating parameters, such as TMP, cross flow velocity, and $\mathrm{pH}$ hydrolysate on both membrane fouling and permeate characteristic, was assessed. The cross flow velocity was regulated by an adjustable DC power supply. The TMP was adjusted by means of needle valves on the feed and permeate sides of the membrane module. The pressures were measured before $\left(P_{\text {in }}\right)$ and after $\left(P_{\text {out }}\right)$ the membrane module and on the permeate side $\left(P_{\text {perm }}\right)$.The TMP is given by:

$$
\mathrm{TMP}=\frac{P_{\text {in }}+P_{\text {out }}}{2}-P_{\text {perm }}
$$

For evaluating the effect of membrane fouling to the hydraulic resistance, the pure water fluxes were measured under the following conditions: (1) for a new membrane, (2) for a membrane which had been fouled by static adsorption, (3) for a membrane which had been fouled by permeation of cassava starch hydrolysate. Additionally, the glucose syrup fluxes under a given set of operating conditions were measured. After each experiment, the membrane was cleaned by aqueous solution of $\mathrm{NaOH}(0.5 \% \mathrm{w} / \mathrm{v})$. The flux of pure water was measured after the membrane cleaning to asses the permanent membrane fouling.

\subsection{Analysis}

Colour is one of the critical parameters for the acceptance of a sugar product. The colour of permeate and feed was determined using a spectrophotometer (Shimadzu, UV-120-02). The colour was the difference of absorbances at 450 and $720-\mathrm{nm}$ wavelengths per unit cell, expressed in reference basis colour, RBC [19]:

$$
\mathrm{RBC}-1000 \frac{A_{420}-2 A_{720}}{b c}
$$

where $A_{420}$ and $A_{720}$ are the absorbance of the solution at 420 and 720 -nm wavelengths, respectively; $b$ is the cell length $(\mathrm{cm}) ; c$ is the concentration $(\mathrm{g} / \mathrm{L})$. Suspended solids were determined in all 
samples by centrifugation of $10 \mathrm{ml}$ of sample in graduated glass tubes at $5000 \mathrm{rev} / \mathrm{min}$ for $30 \mathrm{~min}$ and expressed in volume percentage. Viscosity of the cassava starch hydrolysate was measured with a Brockfield viscometer (LVT, serial 109549). The turbidity of permeate and feed was determined by absorbance measurement at 900 -nm wavelength, where the effect of light absorption is assumed to be zero:

$$
\mathrm{S}=100 \times \frac{A_{900}}{b}
$$

where $\mathrm{S}$ is the turbidity, $A_{900}$ is the absorbance at $900-\mathrm{nm}$ wavelength and $b$ is the cell length (cm).

\subsection{Electron Microscopy}

A digital scanning electron microscope (Philips XL 20) was used to study the surface of clean and fouled membranes. After ultrafiltration of cassava starch hydrolysate for 4 hours at 2 bar and $1 \mathrm{~m} / \mathrm{s}$, the membrane was flushed by deionized water for $15 \mathrm{~min}$ and dried at room temperature in a vacuum desiccator. The membrane was coated with gold-palladium before the photographs were taken.

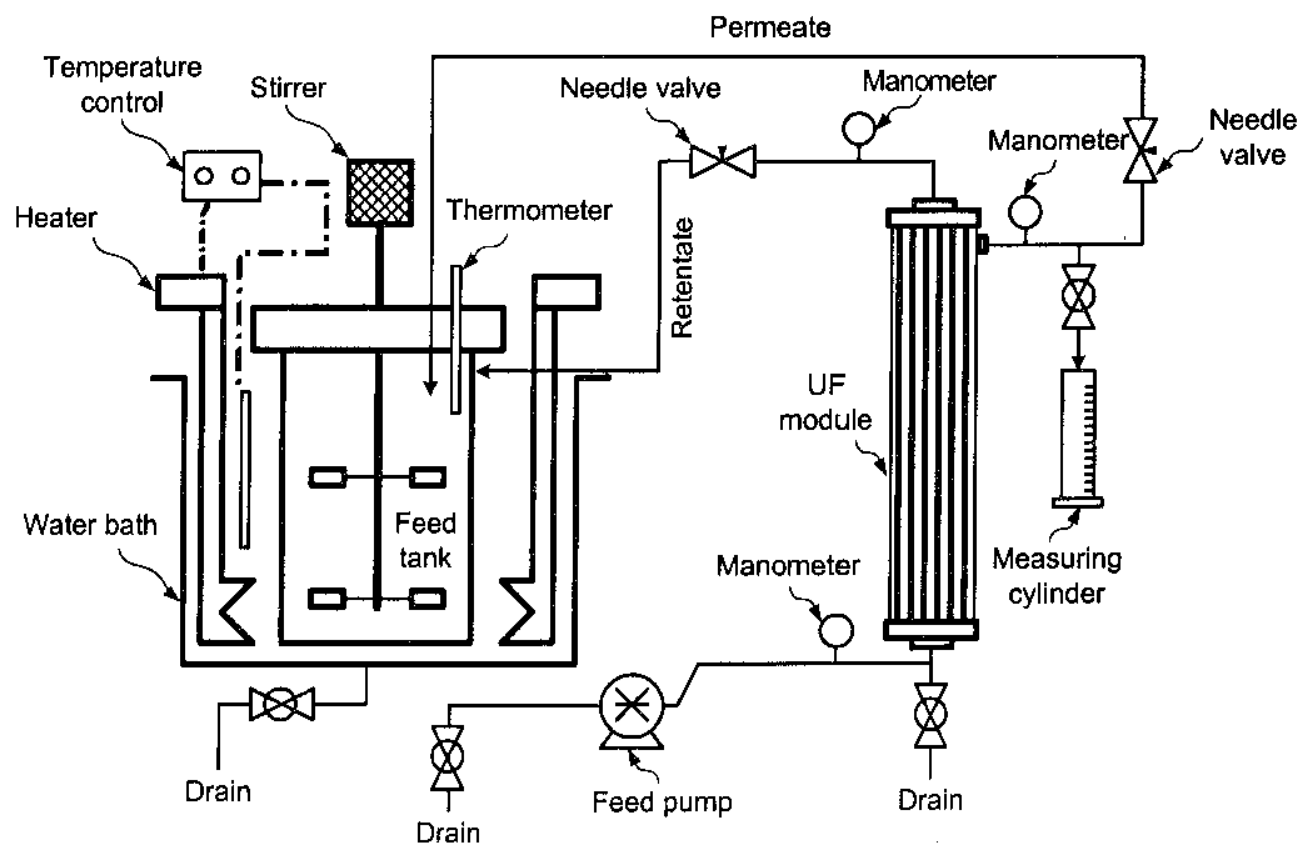

Figure 1 Schematic experimental set-up of the ultrafiltration equipment

\subsection{RESULTS AND DISCUSSION}

\subsection{Effect of TMP}

Typical experimental data for the flux decline during cross flow ultrafiltration of cassava starch hydrolysate through the polyacrylonitrile membrane (PAN) with MWCO $100 \mathrm{kDa}$ at constant pressure of $0.6,1.0,1.5$, and 2.0 bar are shown in Figure 2. All different feed solutions showed the same 


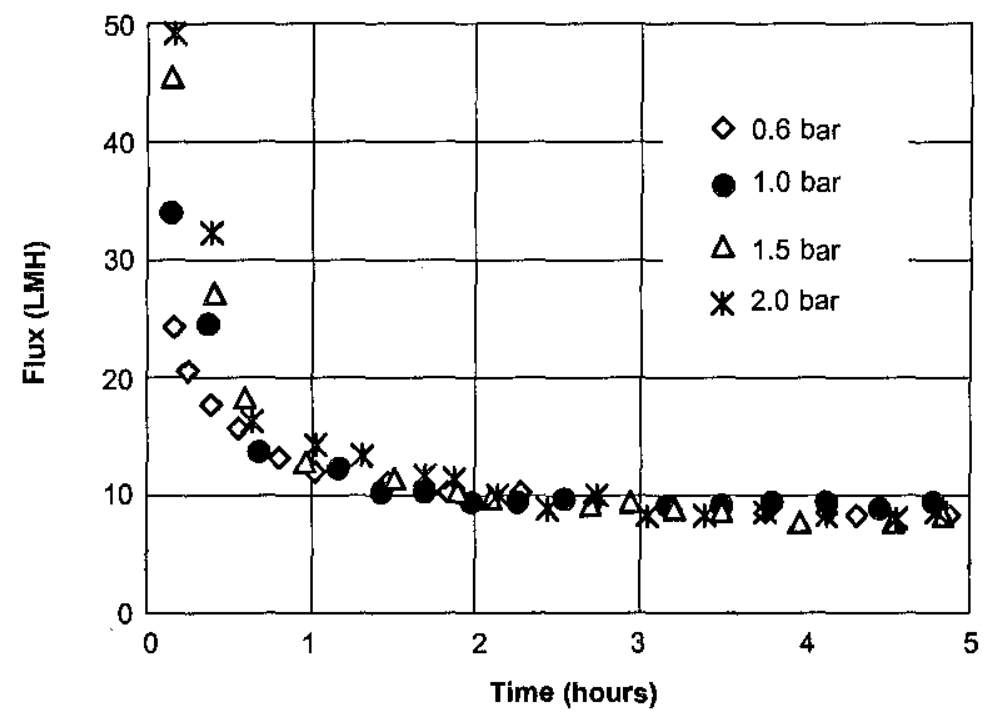

Figure 2 Flux decline during constant pressure cross flow ultrafiltration of cassava starch hydrolysate having $30 \%$ dry solids at $\mathrm{pH} 4.5$, temperature $45 \pm 3^{\circ} \mathrm{C}$, and cross flow velocity $1.0 \mathrm{~m} / \mathrm{s}$

pattern, i.e., sharp flux decline in the first hour, followed by gradual flux decline. The significant loss of flux during the filtration could be attributed to one or more of the following phenomena: (a) adsorption, which refers to a specific interaction between solutes and the membrane polymer, (b) concentration polarization, which refers to the accumulation of retained solutes near the membrane, (c) pore blocking, which refers to solutes penetration into the membrane leading to pore blocking, and (d) gel layer formation, which refers to any additional solutes accumulation at the upper surface of the membrane deposited to form a certain thickness of gel layer.

Several empirical models have been proposed, however, the following two-parameter model [17] was used to describe the data:

$$
J_{t}=J_{s s}+\frac{k}{t}
$$

where $J_{t}$ is the flux at any time, $J_{s s}$ is the steady state flux and $\mathrm{k}$ is the constant describing the rate of fouling. Table 2 shows the values of both $J_{s s}$ and $\mathrm{k}$ at various TMP, temperature $45 \pm 3^{\circ} \mathrm{C}$ and cross flow velocity $1.0 \mathrm{~m} / \mathrm{s}$. The average absolute deviation (AAD) in flux between calculated $\left(J_{i}^{\text {cal }}\right)$ and experimental $\left(U_{i}^{\exp }\right)$ values was used for evaluating the model. For a data set with $\mathrm{N}_{\exp }$ experimental points, AAD is defined as:

$$
\mathrm{AAD}=\frac{1}{N_{\exp }} \sum_{i=1}^{N_{\text {oxp }}}\left|\frac{J_{i}^{\exp }-J_{i}^{\mathrm{cal}}}{J_{i}^{\exp }}\right| \times 100
$$

From Table 2, it can be seen that higher TMP increased $\mathrm{k}$ value. However, the increase of TMP in the range of $0.6-2.0$ bar at cross flow velocity $1.0 \mathrm{~m} / \mathrm{s}$ was not accompanied by a further proportional increase in $J_{s s}$. This confirms that although the cassava starch hydrolysate contains typically less than $1 \%$ of suspended solids (i.e. insoluble impurities such as protein, fat and fibers), it is sufficient to cause the pressure independence of steady state flux, $J_{s s}$. Since there was very little flux decline 
Table 2 Coefficients of the fouling model (Equation (4)) at various TMP, temperature $45 \pm 3^{\circ} \mathrm{C}$ and cross flow velocity $1.0 \mathrm{~m} / \mathrm{s}$

\begin{tabular}{cccc}
\hline TMP(bar) & $\boldsymbol{J}_{s s}$ (LMH) & $\boldsymbol{h}\left(\mathbf{L} / \mathbf{m}^{2}\right)$ & $\mathbf{A A D}(\%)$ \\
\hline 0.6 & 8.4 & 2.5 & 7.8 \\
1.0 & 8.6 & 3.5 & 5.8 \\
1.5 & 7.9 & 5.6 & 9.3 \\
2.0 & 8.0 & 6.6 & 11.3 \\
\hline
\end{tabular}

after 4 hours of filtration, all further data to study the influence of operating parameters on steady state flux were taken after 4 hours.

The selectivity of the membrane was calculated by comparing the turbidity of permeate with those of the feed as follows:

$$
R=\left(1-\frac{S_{P}}{S_{F}}\right) \times 100
$$

where $R$ is the retention in $\%, S_{F}$ is the turbidity of feed, and $S_{P}$ is the turbidity of permeate. As can be seen in Figure 3, the selectivity of the membrane remained unchanged at TMP range of $0.6-2.0$ bar, that was close to $100 \%$.

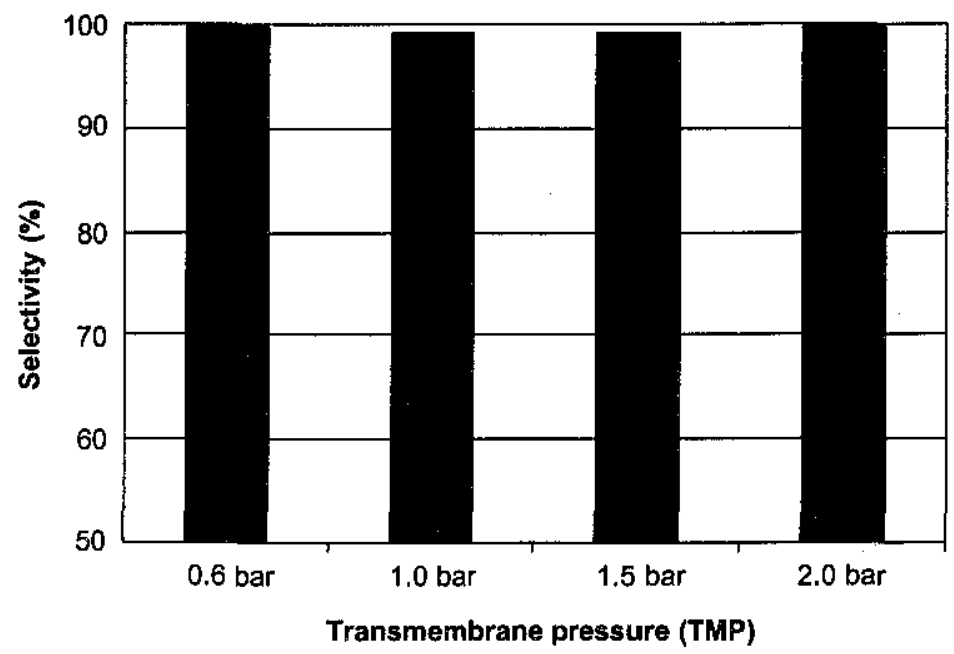

Figure 3 Effect of TMP on membrane selectivity during cross flow ultrafiltration of cassava starch hydrolysate having $30 \%$ dry solids at $\mathrm{pH} 4.5$, temperature $45 \pm 3^{\circ} \mathrm{C}$, and cross flow velocity $1.0 \mathrm{~m} / \mathrm{s}$

\subsection{Effect of $\mathrm{pH}$}

Numerous considerable experimental evidences have proven that membrane fouling during ultrafiltration of solution containing protein can be minimized by adjusting the $\mathrm{pH}$ of feed away from the iso-electric point of the proteins, e.g., cheese whey [20], corn starch hydrolysate [17]. The iso-electric points of $\alpha$-amylase and glucoamylase contained in feed solution were 4.8 and 4.2 , 


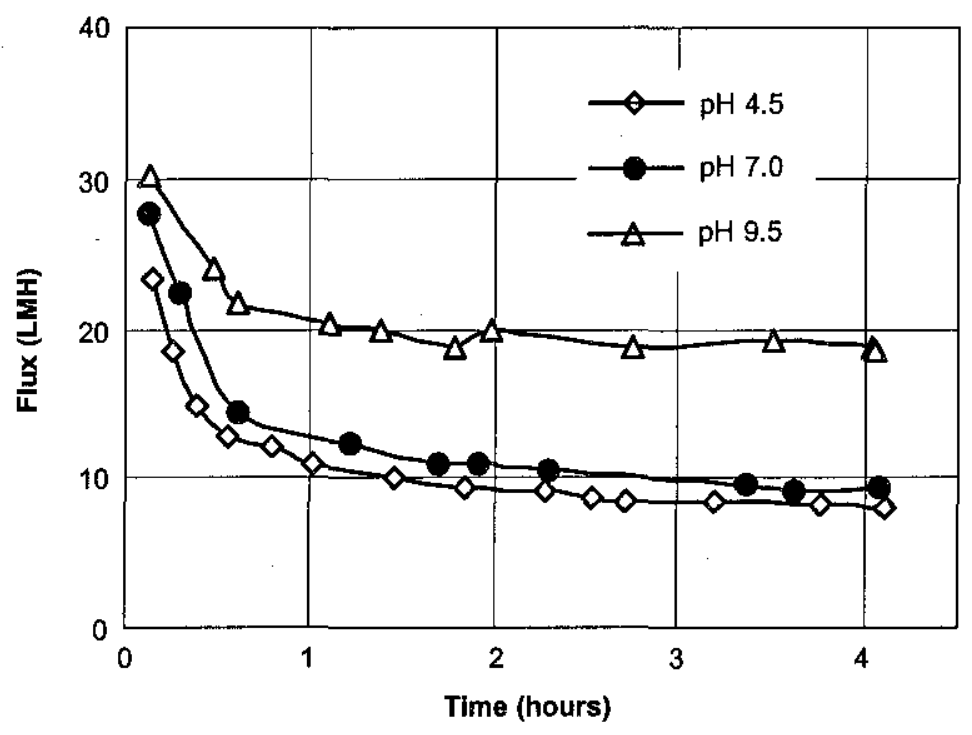

Figure 4 Effect of $\mathrm{pH}$ on membrane fouling during cross flow ultrafiltration of cassava starch hydrolysate having $30 \%$ dry solids at TMP 0.6 bar, temperature $45 \pm 3^{\circ} \mathrm{C}$, and cross flow velocity $1.0 \mathrm{~m} / \mathrm{s}$

respectively [21]. For an ultrafitration system using polymer membrane, however, changes in $\mathrm{pH}$ may affect the membrane selectivity and/or permeate characteristics. Figure 4 shows the effect of $\mathrm{pH}$ on fouling of the PAN membrane by cassava starch hydrolysate. The steady state flux, $J_{s s}$ increased significantly when $\mathrm{pH}$ of the feed was adjusted to alkaline condition. Operating at $\mathrm{pH} 9.5$ would give twice higher $J_{s s}$ than at natural $\mathrm{pH}$ of the feed, however, the membrane selectivity slightly decreased at this $\mathrm{pH}$ (Figure 5). In addition, $\mathrm{pH}$ adjustment from its natural $\mathrm{pH}$ of 4.5 to 9.5 resulted in dark brown clarified glucose syrup expressed as reference basis colour, RBC (Figure 6). Moreover, higher $\mathrm{pH}$ decreased the rate of initial fouling, $k$ (Table 3 ).

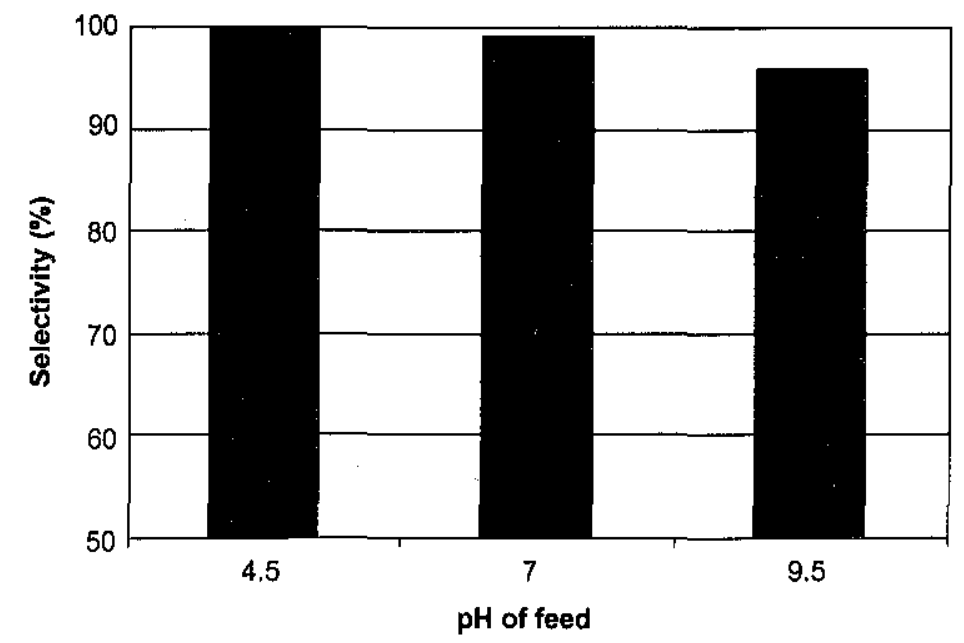

Figure 5 Effect of $\mathrm{pH}$ on membrane selectivity during cross flow ultrafiltration of cassava starch hydrolysate having $30 \%$ dry solids at TMP 0.6 bar, temperature $45 \pm 3^{\circ} \mathrm{C}$, and cross flow velocity $1.0 \mathrm{~m} / \mathrm{s}$ 


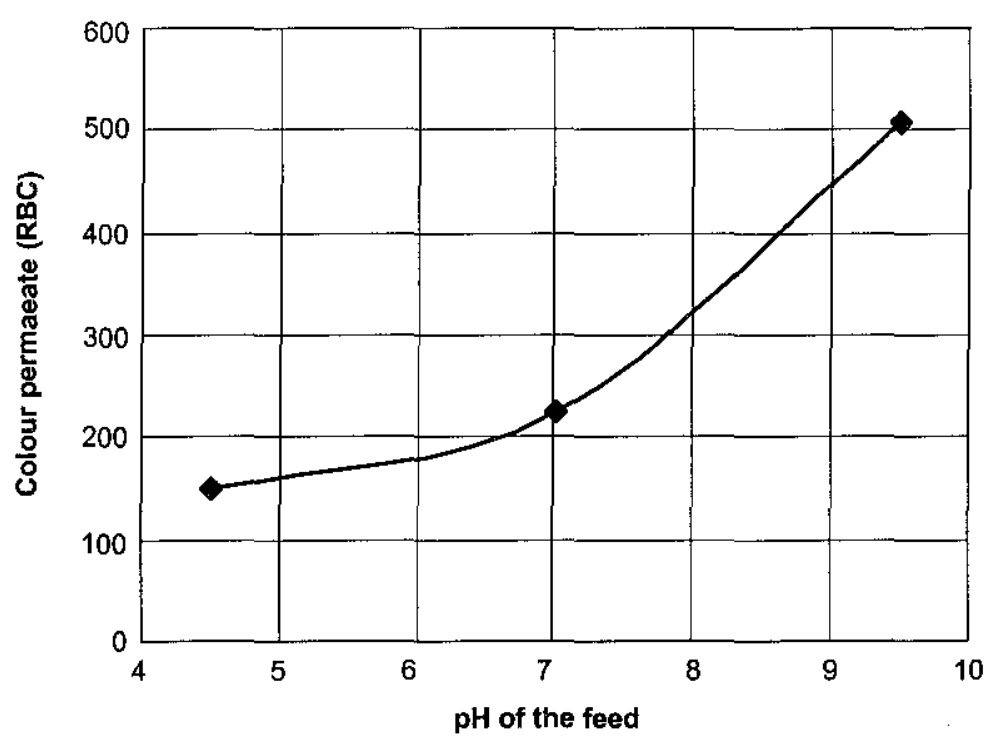

Figure 6 Effect of $\mathrm{pH}$ on the colour of the clarified glucose syrup. Experiments were carried out at TMP 0.6 bar, temperature $45 \pm 3^{\circ} \mathrm{C}$, and cross flow velocity $1.0 \mathrm{~m} / \mathrm{s}$

Table 3 Coefficients of the fouling model (Equation (4)) at various $\mathrm{pH}$, temperature $45 \pm 3^{\circ} \mathrm{C}$, and cross flow velocity $1.0 \mathrm{~m} / \mathrm{s}$

\begin{tabular}{cccc}
\hline pH & $J_{s s}(\mathbf{L M H})$ & $M\left(\mathrm{~L} / \mathbf{m}^{2}\right)$ & Average deviation (\%) \\
\hline 4.5 & 8.4 & 2.5 & 5.2 \\
7.0 & 9.3 & 2.2 & 8.0 \\
9.5 & 18.5 & 1.2 & 3.9 \\
\hline
\end{tabular}

The colour change of the clarified glucose syrup when the $\mathrm{pH}$ of the feed was adjusted to the alkaline conditions could be visually observed. According to Singh and Cheryan [17], sugars undergo browning at alkaline conditions because of the Lobry de Bruyn-van Ekenstein transformation, which proceeds initially through the formation of a 1: 2 trans-ene-diol and then to the production of a brown resin.

\subsection{Effect of Dry Solids Concentration}

Presently, almost all glucose productions from enzymatic starch hydrolysis are conducted at a solid content not more than $40 \%$ so that it eventually needed an evaporation step to concentrate the solution up to the desired solid concentration. This is because, the gelatinized unmodified starch of more than $40 \%$ dry substance is too viscous to be processed in conventional equipment. Nevertheless, hydrolysis of starch at high dry solid will be very attractive because of the increase of energy cost in the recent years. For this reason, the possibility of UF application for clarification of cassava starch hydrolysate having 50\% dry solids is studied. As shown in Figure 7, higher dry solids concentration decreased flux. The significant decrease in flux is conceivably caused by the higher dynamic viscosity. 


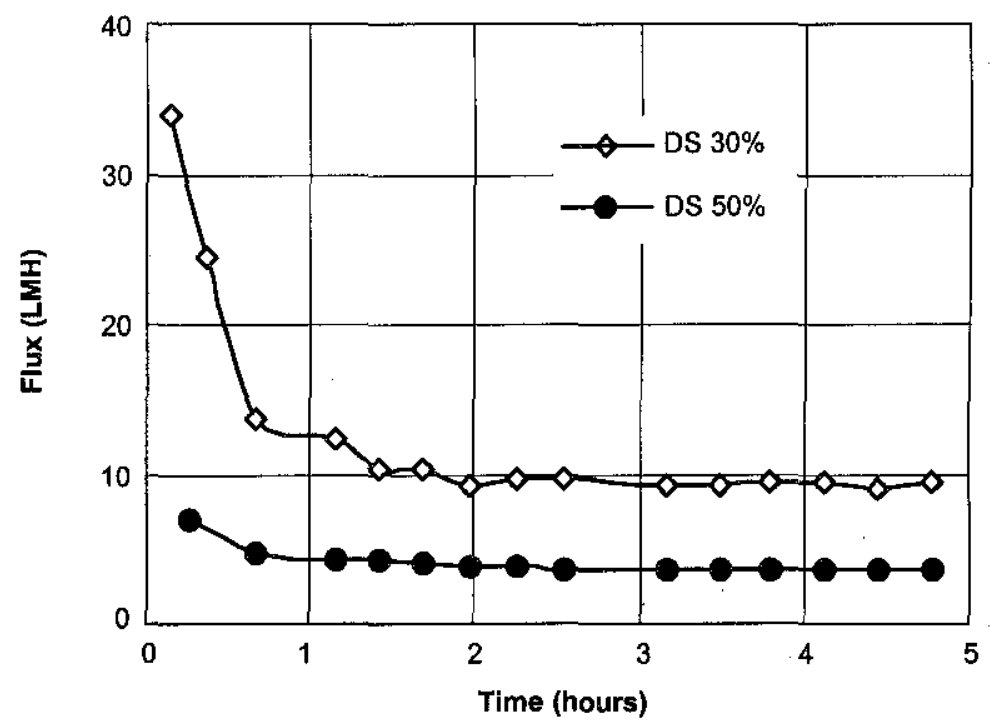

Figure 7 Effect of dry solids concentration on membrane fouling during cross flow ultrafiltration of cassava starch hydrolysate at TMP 0.6 bar, temperature $45 \pm 3^{\circ} \mathrm{C}$, and cross flow velocity $1.0 \mathrm{~m} / \mathrm{s}$

At temperature $40^{\circ} \mathrm{C}$, for example, the increase of dry solids concentration from 30 to $50 \%$ would increase in viscosity by a factor of 3 (Figure 8).

Figure 9 shows the effect of dry solids concentration on the membrane selectivity determined by Equation (6). The membrane selectivity was not significantly different as the dry solids concentration increased from 30 up to $50 \%$. Although the turbidity of feed increased by $70 \%$, the turbidity of permeate remained unchanged. The clarified glucose syrup (permeate) had low colour and no suspended solids.

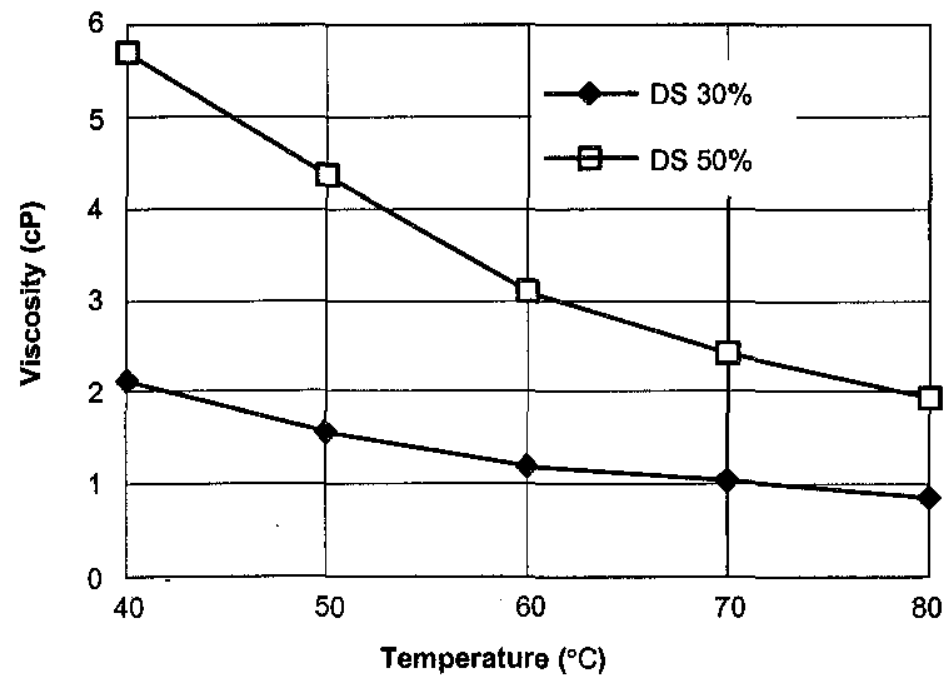

Figure 8 Viscosity of cassava starch hydrolysate as a function of dry solid concentration and temperature 


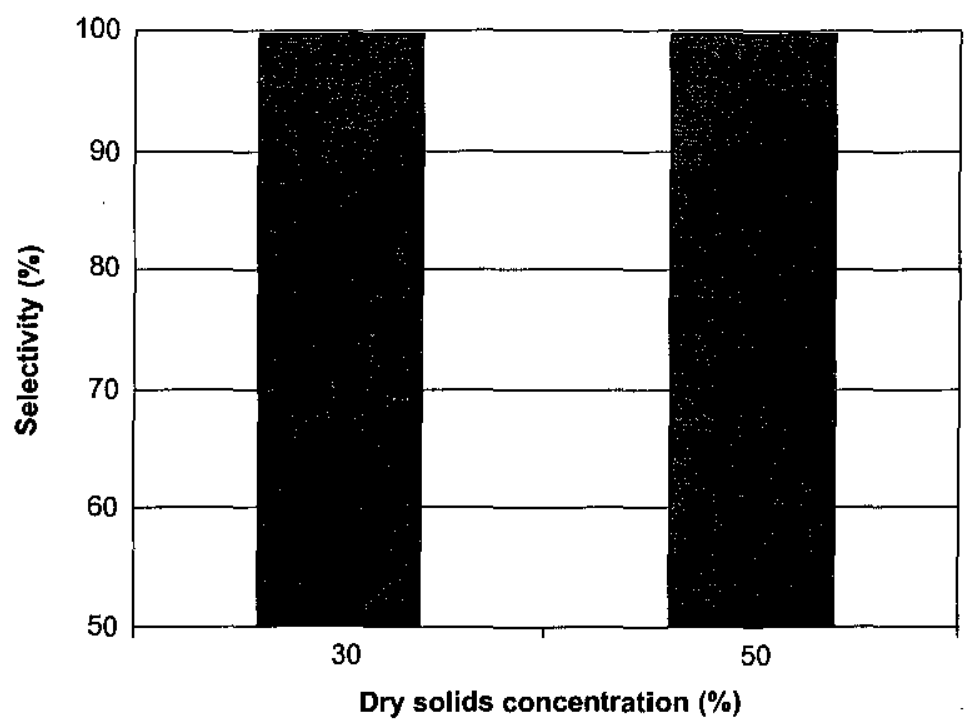

Figure 9 Effect of dry solids concentration on membrane selectivity (TMP $=0.6$ bar, $\mathrm{T}=45 \pm 3^{\circ} \mathrm{C}$, and $\mathrm{v}=1.0 \mathrm{~m} / \mathrm{s}$ )

\subsection{Effect of Cross Flow Velocity}

Considering the above results, one of the operating parameters which can be expected to enhance flux is cross flow velocity. The effect of cross flow velocity on steady state flux is shown in Figure 10. Data of steady state flux was taken after 4 hours. As can be seen, higher steady state flux could be achieved when the cross flow velocity was increased. This indicates that increasing velocity is probably

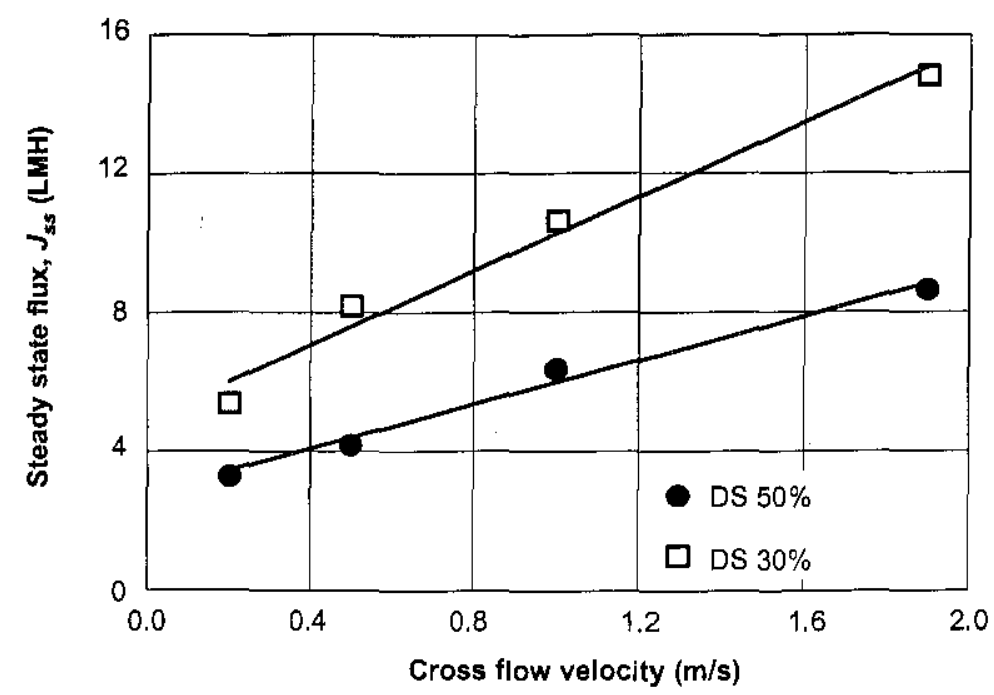

Figure 10 Effect of cross flow velocity on mem brane fouling during the ultrafiltration of cassava starch hydrolysate at TMP 0.6 bar and temperature $45 \pm 3^{\circ} \mathrm{C}$ 


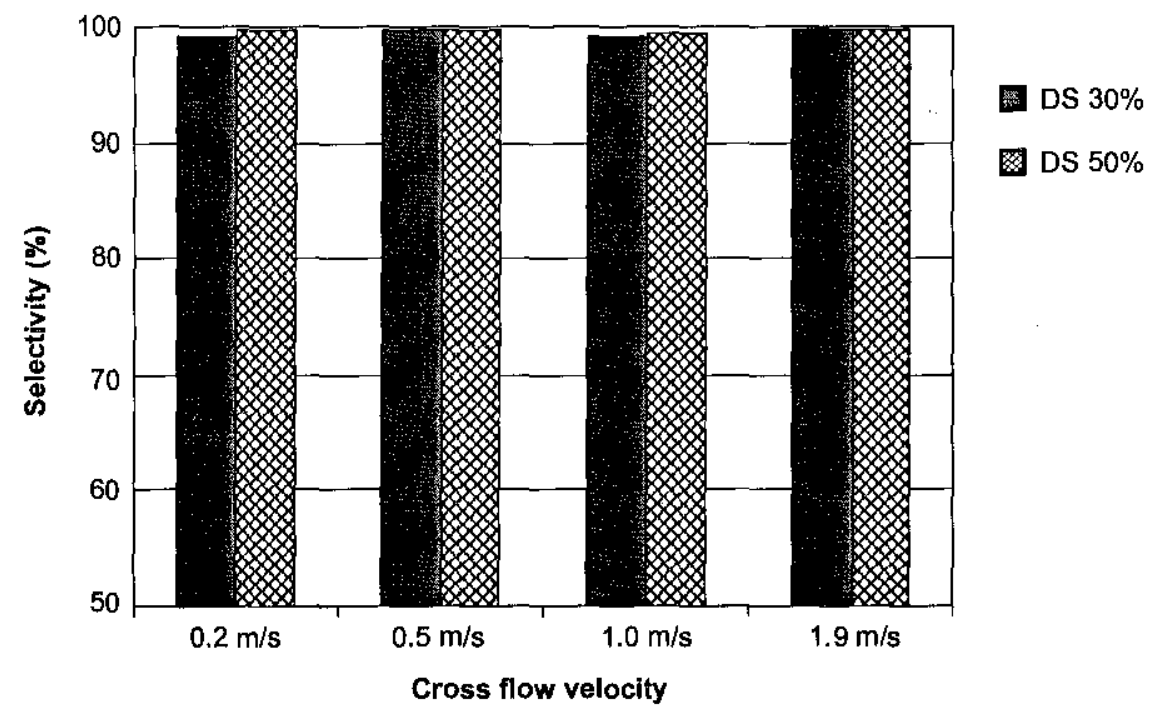

Figure 11 Effect of cross flow velocity on membrane selectivity during the ultrafiltration of cassava starch hydrolysate at TMP 0.6 bar and temperature $45 \pm 3^{\circ} \mathrm{C}$

the easiest way to reduce membrane fouling and maximize flux in clarification of cassava starch hydrolysate by means of cross flow ultrafiltration system using polymer membrane. Unfortunately, the increase of cross flow velocity results in the increase of energy consumption. Moreover, the turbidity of permeate as well as the membrane selectivity were not significantly affected by cross flow velocities (Figure 11).

\subsection{Filtration Resistance}

Any attempt to control membrane fouling requires an understanding of the mechanisms and their contribution. A series resistance model [18] was used to analyze the hydraulic resistances:

$$
J=\frac{\mathrm{TMP}}{\mu R_{t}}
$$

where $J_{s s}$ is the steady state flux, TMP is the transmembrane pressure, and $\mu$ is the viscosity of solution. The total hydraulic resistance, $R_{t}$, is accounted by a number of resistances:

$$
R_{t}=R_{m}+R_{a}+R_{p p}+R_{c p}
$$

where $R_{m}, R_{a}, R_{p p}$ and $R_{c p}$ refer to the intrinsic membrane resistance, adsorptive fouling, pore blocking and concentration polarization, respectively.

Firstly, the membrane resistance, $R_{m}$, was determined by ultrafiltration of deionized water through the clean membrane. From the pure water flux, the membrane resistance could be be calculated as:

$$
R_{m}=\frac{1}{J} \frac{\mathrm{TMP}}{\mu_{\text {water }}}
$$


Secondly, the deionized water was then replaced by a hydrolysate solution at no net TMP (no flux across the membrane). After the membrane was rinsed by deionized water, ultrafiltration of deionized water through the fouled membrane was carried out to determine the adsorptive fouling, $R_{a}$.

$$
R_{1}=R_{a}+R_{m}=\frac{1}{J} \frac{\mathrm{TMP}}{\mu_{\mathrm{water}}}
$$

Thirdly, hydrolysate solution was filtered at TMP 0.6 bar and cross flow velocity $1.0 \mathrm{~m} / \mathrm{s}$ to determine the total membrane resistance, $R_{t}$.

$$
R_{t}=R_{m}+R_{a}+R_{p p}+R_{c p}=\frac{1}{I} \frac{\mathrm{TMP}}{\mu_{\text {permeate }}}
$$

Fourthly, the membrane was then rinsed by deionized water to remove all traces of solution, particularly those of the polarization layer. After cleaning the apparatus, deionized water was filtered through the rinsed membrane under the same conditions. This test was used to determine resistance, $R_{2}$, which is the sum of $R_{m}, R_{a}$ and $R_{p p}$ :

$$
R_{2}=R_{m}+R_{a}+R_{p p}=\frac{1}{J} \frac{\mathrm{TMP}}{\mu_{\text {water }}}
$$

The resistance of concentration polarization, $R_{c p}$, was calculated by subtraction:

$$
R_{c p}=R_{t}-R_{2}
$$

The resistance of pore blocking, $R_{p p}$, was calculated by subtraction:

$$
R_{p p}=R_{2}-R_{1}
$$

The relative distribution of hydraulic resistances of the polyacrylonitrile membrane used for clarification of cassava starch hydrolysate is depicted in Figure 12. The contribution of the various

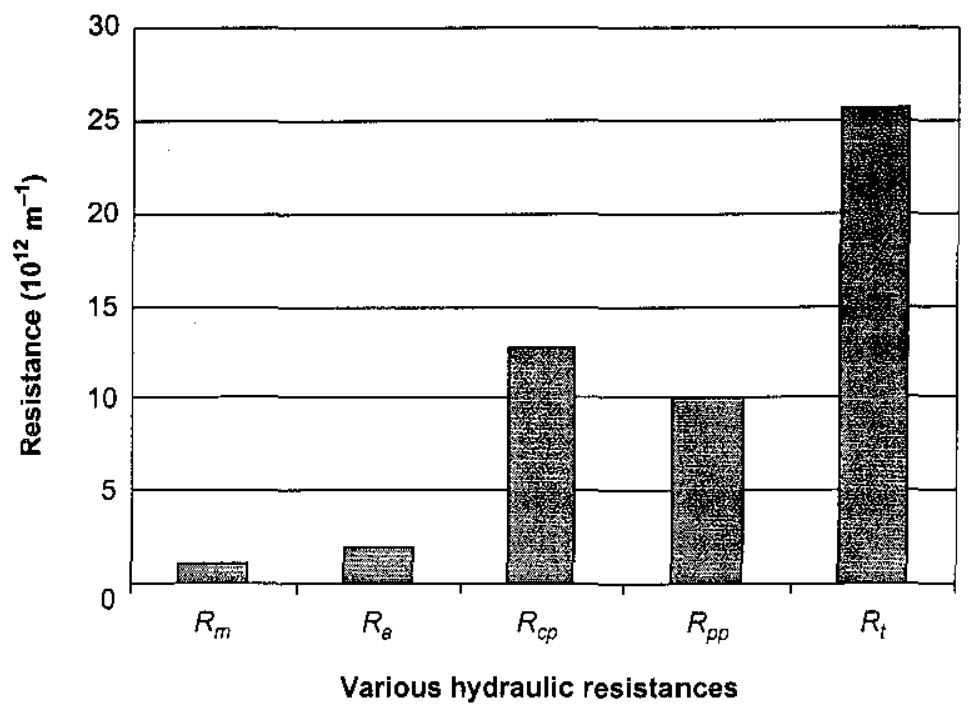

Figure 12 Distribution of various hydraulic resistances during the ultrafiltration of cassava starch hydrolysate at TMP 0.6 bar and temperature $45 \pm 3^{\circ} \mathrm{C}$ 
mechanisms differed significantly. Membrane resistance, $R_{m}$ was negligible with regard to pore blocking or concentration polarization resistance. In other word, concentration polarization, $R_{c p}$ and pore blocking, $R_{p p}$, dominated the total hydraulic resistance, $R_{t}$. Concentration polarization and pore blocking were beyond about 50 and $40 \%$ of the total filtration resistance, respectively. This confirms why the steady state flux increases significantly when the cross flow velocity is increased.

\subsection{Scanning Electron Microscopy}

A representative scanning electron microscopy (SEM) photograph of the cross section of a clean membrane is shown in Figure 13. The membrane has a finger with structure inner and outer skins (double skins). The structure is similar to numerous photographs published in the literature and in catalogue. Such structure usually gives a sufficient mechanical strength; however, it is difficult to remove foulant entrapped into membrane pores.

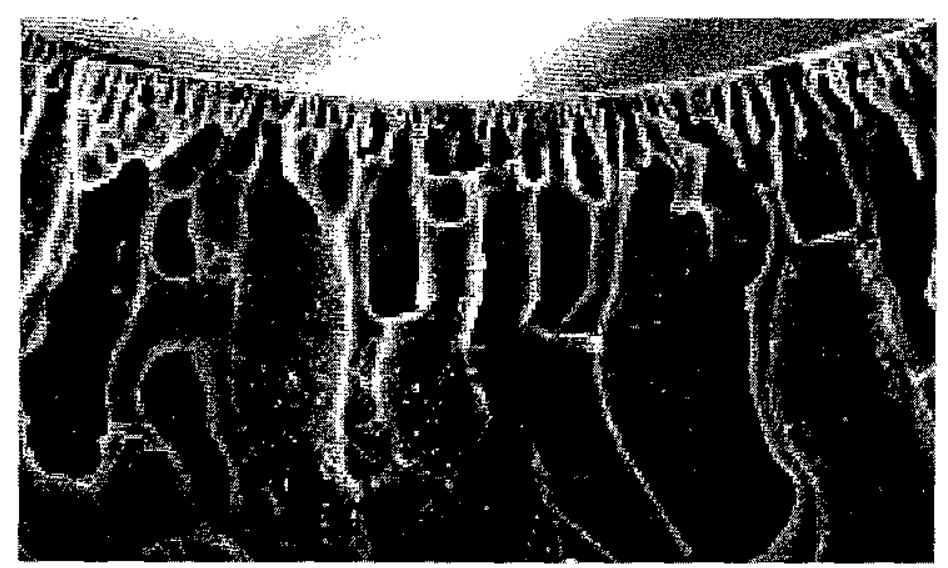

Figure 13 SEM of the cross section of the clean membrane used in this study (Magnification: 150X)

The cassava starch hydrolysate at its natural $\mathrm{pH}$ resulted in fouling layers on the membrane surface (Figure 14). A representative SEM photograph of fouling layer on the membrane surface is shown in Figure 15. The fouling layer is presumed multi layer. Hence, it is sufficient to cause a great loss of flux during filtration. Such fouling layer may be relatively easy remove by a simple cleaning procedure.

\subsection{Membrane Cleaning}

As discussed above, foulants accumulated on the membrane surface and/or membrane pores caused a significant loss of membrane performance during filtration. This change continued throughout the process. Hence, the foulants must be periodically removed from the membrane structure using an appropriate cleaning procedure to restore the membrane performance. The development of an appropriate cleaning strategy requires an understanding of the physical and chemical characteristics of the key foulants, the membrane polymer and module, and the various cleaning solutions so that the cleaning procedure must effectively remove and/or dissolve the foulants while not exceeding the mechanical or chemical limits of the membrane polymer [14]. 


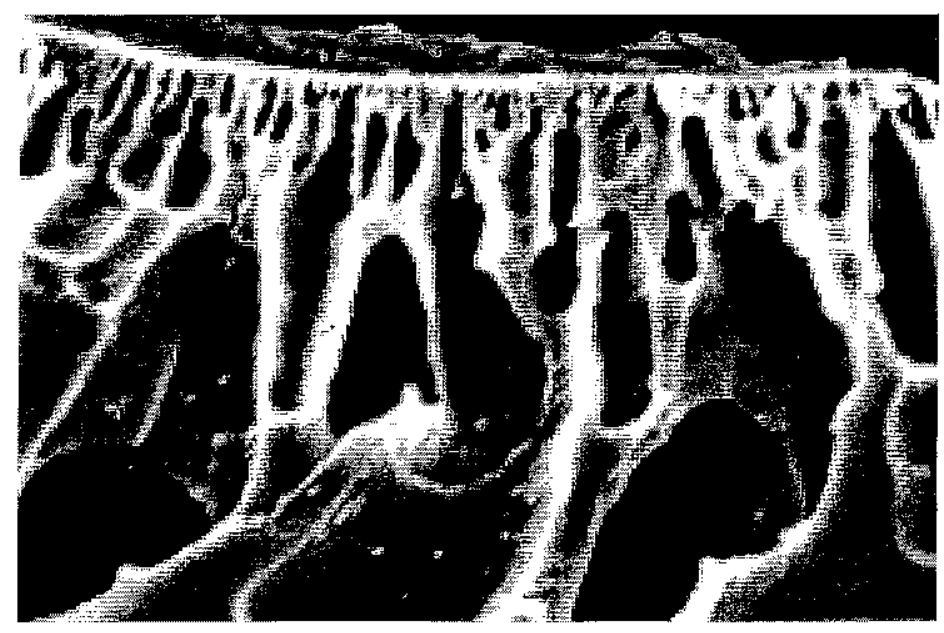

Figure 14 SEM of cross section of a fouled membrane during the ultrafiltration of cassava starch hydrolysate at TMP 0.6 bar and temperature $45 \pm 3^{\circ} \mathrm{C}$ (Magnification: $150 \mathrm{X}$ )

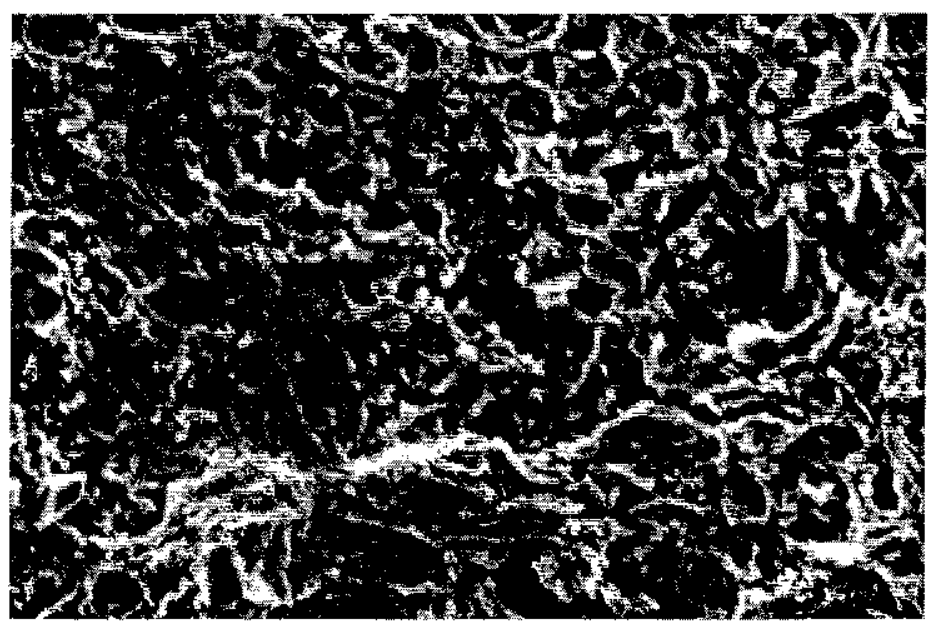

Figure 15 SEM of fouling layer deposited on the inner membrane surface (Magnification: 150X)

According to the experiments, the PAN membrane could be regenerated by the following procedure:

- $5 \mathrm{~min}$ surface cleaning of lumen side with tap water at room temperature

- 2 min internal cleaning from shell to lumen (backwash) with $0.5 \% \mathrm{NaOH}$ solution at temperature $57 \pm 3^{\circ} \mathrm{C}$

- 2 min internal cleaning (backwash) with $0.5 \% \mathrm{HCl}$ solution at temperature $57 \pm 3^{\circ} \mathrm{C}$

- $5 \mathrm{~min}$ rinse of both lumen and shell sides with deionized water at room temperature

Figure 16 shows the pure water fluxes which were recovered after the membrane was cleaned. As can be seen, a significant pure water flux could be achieved after internal cleaning with $0.5 \% \mathrm{NaOH}$ solution at temperature $57 \pm 3^{\circ} \mathrm{C}$. Further internal cleaning with $0.5 \% \mathrm{HCl}$ solution at temperature 


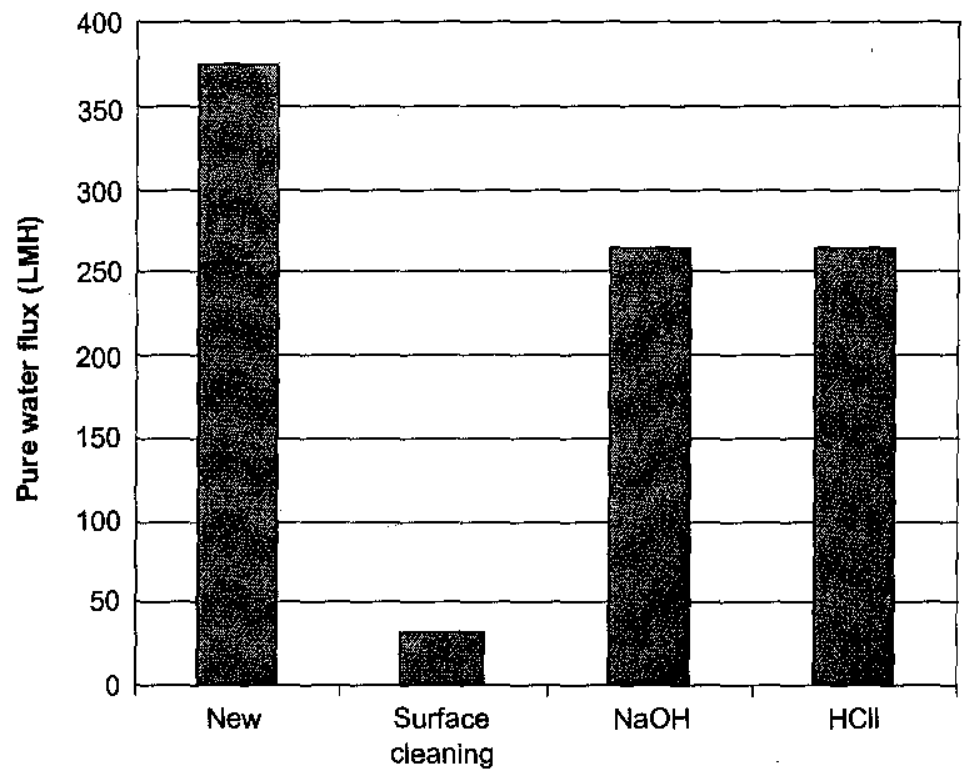

Figure 16 The pure water fluxes which were recovered after every cleaning procedure. Measurements were conducted at TMP 1 bar

$57 \pm 3^{\circ} \mathrm{C}$ did not improve the water flux. Therefore, internal cleaning with $0.5 \% \mathrm{HCl}$ solution was not conducted for further membrane cleaning. The membrane performance could be restored approximately $45 \%$ compared to its initial performance as shown in Figure 17.

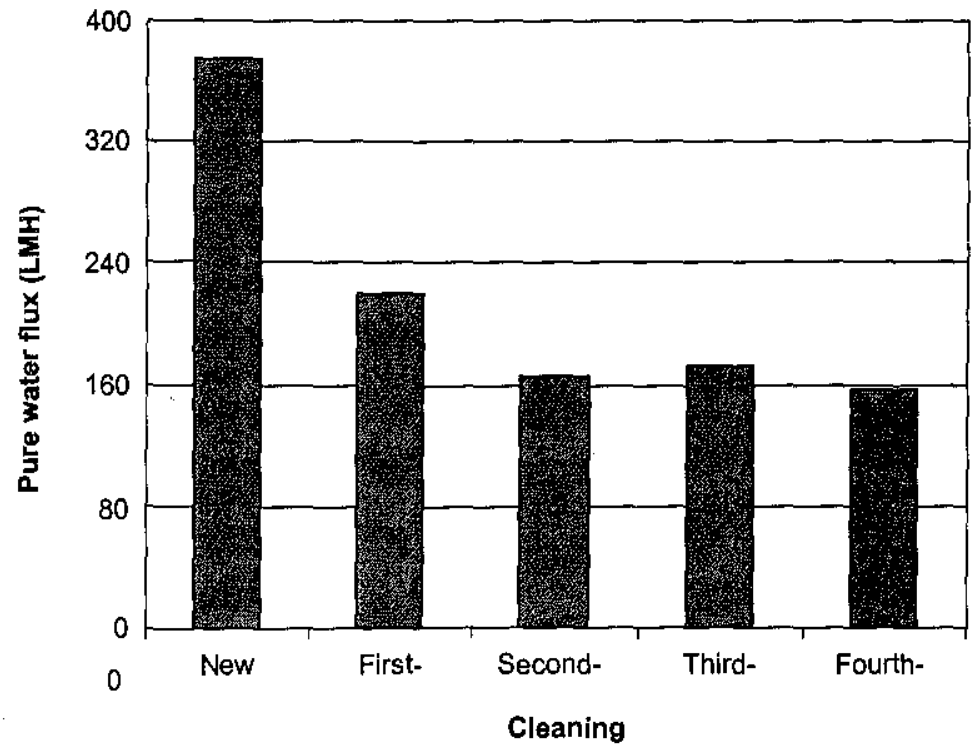

Figure 17 The pure water fluxes which were recovered after the membrane was cleaned. Measurements were conducted at TMP 1 bar 


\subsection{CONCLUSIONS}

Cross flow ultrafiltration using a polymer membrane is a potential technique to remove insoluble impurities from cassava starch hydrolysate. Operating at natural $\mathrm{pH}$ of 4.5 , the membrane selectivity was close to $100 \%$. Transmembrane pressure higher than 1.0 bar was not effective to improve the flux. Increasing cross flow velocity is probably the easiest way to reduce membrane fouling and maximize flux, provided the TMP was kept low. The steady state flux, $J_{s s}$ increased significantly when $\mathrm{pH}$ of the feed was adjusted to alkaline condition; however, this resulted in dark brown clarified glucose syrup. Moreover, the membrane selectivity slightly decreased at $\mathrm{pH} 9.5$.

Evaluation of hydraulic resistance indicated that the polarization concentration and pore blocking constituted the main parts of the total mass transfer resistance. Concentration polarization and pore blocking were beyond approximately 50 and $40 \%$ of the total filtration resistance, respectively. Moreover, scanning electron microscopy showed that extensive fouling layer was deposited on the membrane surface. Finally, the developed cleaning procedure could restore membrane performance approximately $45 \%$ compared to its initial performance.

\section{ACKNOWLEDGEMENTS}

Financial support was received from the Minister of State for Research and Technology, Republic of Indonesia under Grant No. 30/Perj-IN/RUK/KRT/III/2003. The support given by PT. Raya Sugarindo Inti, Dept. Chemical Engineering Institut Teknologi Bandung, and downstream processing laboratory Institut Teknologi Bandung, in the form of facilities is gratefully acknowledged. The authors are indebted to Dian Kurniawan for the technical assistance.

\section{REFERENCES}

[1] Patil, S. K. 1991. Starch Properties, Modification, and Applications in Foods. Part 1. Eur. Food Drink Rev. 72-84.

[2] Walon, R. G. P. 1975. Enzymatic Hydrolysis of Granular Starch. U.S. Patent No. 3, 922,200.

[3] Pongsawatmanit, R., P. Thanasukam, and S. Ikeda. 2002. Effect of Sucrose on RVA Viscosity Parameters, Water Activity and Freezable water Fraction of Cassava Starch Suspensions. ScienceAsia. 28: 129-134.

[4] Simms, R. L. 1985. The Technology of Corn Wet Milling, in Starch Conversion Technology. G. M. A. van Beynum, and J. A. Roels (Eds.). New York: Marcel Dekker. 47-72.

[5] Basso, A. J. 1982. Vacuum Filtration Using Filteraids. Chem. Eng. 89: 159-160, 162.

[6] Kuske, E. A., and D. L. Bonnett. 1977. Versatile Filteraid Helps Assure Precise Quality for Corn Syrups. Food Engineering. 49: 92, 94.

[7] Singh, N., and M. Cheryan. 1998. Process Design and Economic Analysis of A Ceramic Membrane System for Microfiltration of Corn Starch Hydrolysate. J. Food Eng. 38: 57-67.

[8]. Madsen, R. F. 1973. Application of Ultrafiltration and Reverse Osmosis to Cane Juice. Int. Sugar J. 75: 163-167.

[9] Kishihara, S., S. Fujii, and M. Komoto. 1981. Ultrafiltration of Cane Sugar: Influence of Flux and Quality of Permeate. Int. Sugar J. 83: 35-39.

[10] Kishihara, S., S. Fujii, and M. Komoto. 1983. Improvement of Flux in Ultrafiltration of Cane Juice. Int. Sugar J. 85: 99-102. 
[11] Bahrumsyah, M. Purwasasmita, and I. G. Wenten. 1999. Ultrafiltrasi untuk Klarifikasi Nira Tebu: Transmisi Sukrosa pada Berbagai Kondisi Operasi. Proc. National Seminar on Chem. Eng. Institut Teknologi Bandung. V157-V163.

[12] Wenten, I G., H. Susanto, and M. Purwasasmita. 2000. Ultrafiltrasi Sebagai Alternatif Peningkatan Efisiensi Proses Klarifikasi pada Industri Gula. Reaktor, 4: 22-28.

[13] Gyura, J., Z. Seres, G. Vatai, and E. B. Molnar. 2002. Separation of Non-sucrose Compounds from the Syrup of Sugar-beet Processing by Ultra- and Nanofiltration using Polymer Membranes. Desalination. 148: 49-56.

[14] Zeman, L. J., and A. L. Sydney. 1996. Microfiltration and Ultrafiltration: Principles and Applications. $1^{\text {st }}$ ed. New York: Marcel Dekker Inc. 397.

[15] Mulder, M. 1996. Basic Principles of Membrane Technology. $2^{\text {nd }}$ ed. Dodrecht: Kluwer Academic Publishers. 416.

[16] Jonsson, A-S., and G. Tragardh. 1990. Fundamental Principles of Ultrafiltration. Chem. Eng. Process. 27: 67-81.

[17] Singh, N., and M. Cheryan. 1997. Fouling of a Ceramic Microfiltration Membrane by Corn Starch Hydrolysate. J. Membr. Sci. 135: 195-2002.

[18] Ousman, M., and M. Bennaser. 1995. Determination of Various Hydraulic Resistance During Cross-Flow Filtration of a Starch Grain Suspension Through Inorganic Membranes. J. Membr. Sci. 105: 1-21.

[19] Prancoast, H. M., and W. R. Junk. 1980. Handbook of Sugars. $2^{\text {nd }}$ ed. Westport, Connecticut: Avi Publishing Company Inc. 536-537.

[20] Cheryan, M. 1998. Ultrafiltration and Microfiltration Handbook. Lancaster: Technomic Publishing Company Inc. 259-26.

[21] Pazur, J. H. 1965. Enzymes in Synthesis and Hydrolysis of Starch. In Starch: Chemistry and Technology. R. L. Whistler, and E. F. Paschall (Eds.). New York: Academic Press Inc. 133-175. 